\title{
O intuicionismo em Rawls, o emotivismo em Macintyre e a técnica decisória da ponderação entre princípios constitucionais: comentários sobre o caso Ellwanger*
}

The intuitionism in rawls, the emotivism in macintyre and the weighting between constitutional principles: comments on the case ellwanger

Guilherme Valle Brum ${ }^{1}$

\section{Resumo}

O trabalho discute a forma como a técnica decisória da ponderação entre princípios constitucionais vem sendo utilizada pela Suprema Corte brasileira, tendo como objeto de análise o chamado Caso Ellwanger, valendo-se, para a discussão, dos argumentos de John Rawls e de Alasdair MacIntyre, nas críticas que fizeram, respectivamente, às correntes filosóficas intuicionista e emotivista.

Palavras-chave: Ponderação entre princípios constitucionais. Intuicionismo. Emotivismo. Caso Ellwanger.

\begin{abstract}
The paper discusses how the operative technique of weighting between constitutional principles has been used by the Brazilian Supreme Court, having as object of analysis the so called Case Ellwanger and drawing upon of the arguments of John Rawls and Alasdair MacIntyre in the criticisms made, respectively, to the intuitionism and emotivism.
\end{abstract}

Keywords: Weighting between constitutional principles. Intuitionism. Emotivism. Case Ellwanger.

* Recebido em: abril de 2012. Aprovado em: abril de 2012.

1 Especialista em Direito Constitucional (UNISUL/SC) e Mestrando em Direito (UniCEUB/ DF). Procurador do Estado do Rio Grande do Sul. 


\section{Introdução}

Na definição de Ronald Dworkin, os "casos difíceis" são aqueles que não podem ser submetidos a uma regra de direito clara, estabelecida de antemão por alguma instituição. Porém, mesmo nessa hipótese, uma das partes permanece possuindo o direito de ganhar a causa $\mathrm{e}$ o juiz, por seu turno, continua tendo o dever de descobri-lo (o direito da parte vencedora), e não de inventá-lo retroativamente. ${ }^{2}$ A técnica decisória comumente utilizada no julgamento dos hard cases é a chamada "ponderação entre princípios constitucionais". E é exatamente essa técnica que se fará objeto do presente estudo. Pretendemos verificar se o uso da ponderação ou sopesamento entre princípios, em um dos casos mais emblemáticos e difíceis apreciados pela Suprema Corte brasileira, ${ }^{3}$ cumpriu o papel para o qual foi forjada.

Valer-nos-emos, para esta abordagem, de contribuições provenientes do debate entre comunitarismo e liberalismo, impulsionados pela publicação, no ano de 1971, do texto "Uma Teoria da Justiça" (A Theory of Justice), de John Rawls. Em uma descrição muito sintética, podemos caracterizar o liberalismo como um pensamento que acredita na existência de critérios de justificação para os valores da vida humana, independente de crenças comuns aceitas em cada sociedade, defendendo que pessoas racionais podem concordar que alguns valores são mais válidos do que outros, segundo critérios de validade universais. O ser humano, portanto, para os liberais, é um ser moral dotado de sentimento de justiça, capaz de estabelecer seus projetos de vida de modo autônomo, podendo atuar de acordo com princípios universais aceitos pelos homens, seres racionais, livres e iguais que são.

2 DWORKIN, Ronald. Levando os direitos a sério. Trad. Nelson Boeira. São Paulo: M. Fontes, 2010. p. 127.

3 Trata-se do Caso Ellwanger, ao qual voltaremos oportunamente. de maneira solipsista, se continuará ou não pertencendo a uma determinada comunidade. ${ }^{4}$

O interessante é que, apesar dessas diferentes visões de mundo, é possível identificarmos, em duas das talvez mais notáveis teorias sobre o liberalismo e o comunitarismo, uma crítica semelhante a uma peculiar corrente de pensamento chamada para uns de "intuicionismo" e, para outros, de "emotivismo". Estamos falando, respectivamente, da já referida teoria da justiça do liberal Rawls ${ }^{5}$ e do trabalho intitulado "Depois da Virtude" (After Virtue), do comunitarista Alasdair MacIntyre. ${ }^{6}$ Parece-nos que as críticas dirigidas por esses filósofos ao intuicionismo/emotivismo podem ser utilizadas para uma abordagem também crítica da técnica decisória da ponderação entre princípios constitucionais, pelo menos no que se refere ao seu uso na prática da jurisprudência brasileira. A nossa intenção é lançar um olhar questionador sobre o uso da ponderação no chamado Caso Ellwanger, julgado pelo Supremo Tribunal Federal.

\section{A crítica de John Rawls ao intuicionismo}

John Rawls, em um trecho da sua clássica teoria sobre a justiça, critica a corrente de pensamento intuicionista. O filósofo entende essa corrente como sendo aquela que defende a existência de "[...] um conjunto irredutível de princípios fundamentais que devemos pesar e comparar, perguntando-nos qual equilíbrio, no nosso juízo ponderado, é o mais justo"? Como o próprio nome indica, trata-se de uma aposta em nossas intuições e na capacidade de, por meio delas, alcançarmos juízos ponderados que nos levariam a uma solução para qualquer dilema moral. É dizer: partindo de nossa intuição e pesando e comparando princípios fundamentais em oposição, resolveríamos os desacordos sobre os valores que devem reger nossa vida em sociedade. Além disso, os intuicio-

${ }^{4}$ Um bom desenvolvimento da discussão entre liberais e comunitaristas sobre a justificação dos valores sociais pode ser encontrada em: THIGPEN, Robert B.; DOWNING, Lyle A. Liberal and communitarian approaches to justification. The Review of Politics, v. 51, n. 4, p. 533, 1989.

5 RAWLS, John. Uma teoria da justiça. Trad. Jussara Simões. São Paulo: M. Fontes, 2008.

6 MACINTYRE, Alasdair. Depois da virtude: um estudo em teoria moral. Trad. Jussara Simões. São Paulo: EDUSC, 2001.

7 RAWLS, John. Uma teoria da justiça. Trad. Jussara Simões. São Paulo: M. Fontes, 2008. p. 41. 
nistas negam a existência de critérios de ordem superior capazes de orientar a decisão sobre qual o peso a ser dado aos princípios rivais de justiça.

O intuicionismo, pois, caracteriza-se por aceitar uma pluralidade de princípios fundamentais que podem entrar em conflito, oferecendo soluções distintas para os problemas de justiça, bem como por não apresentar um método ou regra de prioridade segura para a comparação desses princípios entre si. “Temos de chegar ao equilíbrio por meio da intuição, por meio do que nos parece aproximar-se mais do que é justo". Rawls apresenta-nos um interessante exemplo de raciocínio intuicionista, fazendo-o para demonstrar sua insustentabilidade: para atingirmos a ideia de salário justo, seria necessário que equilibrássemos critérios concorrentes diversos, como "as credenciais de capacitação, treinamento, esforço, responsabilidade e riscos do trabalho", levando em conta, outrossim, a noção de necessidade. Presume-se, portanto, que pessoa alguma chegaria a uma solução sobre a definição de salário justo valendo-se de apenas um desses critérios, de modo que seria imperioso, para isso, que alcançasse um equilíbrio entre eles. Dessa forma, de acordo com o pensamento do autor de $A$ Theory of Justice, "[...] aqueles que têm interesses diferentes provavelmente darão ênfase aos critérios que favoreçam seus objetivos", o que poderia acarretar que as pessoas que possuem, por exemplo, maior educação e capacidade dessem preferência aos critérios de habilidade e treinamento, ao passo que os menos instruídos defenderiam o critério da necessidade. "Mas - argumenta Rawls - as nossas ideias cotidianas de justiça não sofrem influência só da nossa situação; nelas também repercutem os costumes e as expectativas vigentes." $\mathrm{E}$ assim sendo, isso nos levaria a indagar sobre os critérios com os quais deveríamos avaliar a justiça e a legitimidade desses próprios costumes e expectativas, tarefa cuja resolução não seria satisfatória, caso nos valêssemos apenas de nossa intuição e juízos ponderados.

O pensador vai além. Traz-nos uma reflexão sobre a possibilidade de o intuicionismo contribuir para a definição dos problemas da justiça em relação aos objetivos de política social. Para tanto, John Rawls supõe que "[...] a eficiência alocativa, o pleno emprego, uma renda

\footnotetext{
8 RAWLS, John. Uma teoria da justiça. Trad. Jussara Simões. São Paulo: M. Fontes, 2008. p. 41.

9 Ibidem, p. 43.
}

nacional mais elevada e sua distribuição mais igualitária sejam aceitos como objetivos sociais". Feita a ponderação entre esses fins estatais, parece plausível dizer que valores como salários justos e tributação justa receberiam a devida ênfase. O intuicionismo pode levar-nos a esses valores e servir de base para a decisão. Porém, ainda assim, "[...] ficamos com o apelo à intuição na ponderação dos próprios fins políticos de ordem superior" que, embora se destinem a justificar os objetivos da política social e devam, por conseguinte, definir o equilíbrio desses objetivos, podem corresponder a convicções políticas extremamente divergentes. Por exemplo, poderíamos conceber que a estrutura básica da sociedade deve ser planejada em conformidade com dois princípios: produzir o maior saldo líquido de satisfação e distribuir as satisfações de maneira igualitária. O primeiro princípio atua como um modelo de eficiência, instigando-nos à produção do máximo possível, permanecendo inalteradas as demais condições, enquanto o segundo princípio funciona como um modelo de justiça, oferecendo-nos restrições à busca do bem-estar agregado pelo nivelamento da distribuição de vantagens. $O$ problema é que o intuicionismo não nos apresenta uma regra de prioridade para decidirmos como esses princípios devem equilibrar-se entre si. ${ }^{10} \mathrm{E}$ assim, permanecemos na exclusiva dependência do acerto de nossas intuições.

A essa altura parece fácil perceber que a nota distintiva do pensamento intuicionista é o lugar destacado que confere ao recurso a nossas capacidades intuitivas, negando a existência de uma solução útil para o problema da prioridade. E a crítica rawlsiana é direcionada principalmente a essa falta de critérios que reduzam a discricionariedade na aferição do valor que deve ser priorizado no conflito entre princípios fundamentais. Embora não negue a influência dos juízos intuitivos no desenvolvimento dessa tarefa, Rawls acredita que deveríamos, ao trabalhar com o problema da prioridade, reduzir nossa dependência em relação a esses juízos. Nas suas exatas palavras: ${ }^{11}$

$$
\begin{aligned}
& \text { Não há motivo para supor que podemos evitar } \\
& \text { todos os apelos à intuição, de qualquer espécie, } \\
& \text { ou que deveríamos tentar fazê-lo. A finalidade } \\
& \text { prática é alcançar um consenso de julgamento } \\
& \text { razoavelmente confiável, a fim de obter uma } \\
& \text { concepção comum de justiça. Se os juízos intui- }
\end{aligned}
$$

\footnotetext{
${ }^{10}$ RAWLS, John. Uma teoria da justiça. Trad. Jussara Simões. São Paulo: M. Fontes, 2008. p. 44-45.

${ }^{11}$ Ibidem, p. 54.
} 
tivos das pessoas sobre a prioridade forem semelhantes, não importa, na prática, que elas não consigam formular os princípios que justificam essas convicções, ou mesmo se esses princípios existem. Juízos opostos, porém, criam uma dificuldade, pois a base para arbitrar exigências conflitantes torna-se obscuras. Assim, nosso objetivo deveria ser formular uma concepção de justiça que, por mais que apele à intuição, ética ou prudencial, se incline a fazer convergir nossos juízos ponderados acerca da justiça.

E essa tentativa de formular uma concepção de justiça que, por mais que apele à intuição, ética ou prudencial, se incline a fazer convergir nossos juízos ponderados acerca da justiça, é precisamente o que John Rawls tenta fazer na sua sofisticada teoria, notadamente com os conceitos, por ele criados, de "posição original" e "equilíbrio reflexivo". Se o filósofo atinge seu objetivo, não é nossa intenção verificar neste trabalho. O que pretendemos ter deixado claro é em que reside o foco da sua crítica ao intuicionismo, para que seja possível partirmos para a análise do "emotivismo" na obra de MacIntyre, de modo a aferirmos os pontos de convergência com essa crítica rawlsiana, possibilitando-nos, enfim, avançar na análise da ponderação entre princípios levada a efeito pela Suprema Corte brasileira no caso selecionado para exame.

\section{A crítica de Alasdair Macintyre ao emotivismo}

O filósofo comunitarista Alasdair MacIntyre, em sua teoria moral (After Virtue: A Study in Moral Theory), descreve uma doutrina - emotivismo - que apresenta identidade com o intuicionismo. É interessante notar que, apesar de MacIntyre ser um comunitarista e Rawls um liberal, ambos criticam as teorias que apostam em juízos pessoais e intuições para a justificação dos valores que subjazem a nossa vida em sociedade.

\section{Na definição macIntyriana, o emotivismo}

\begin{abstract}
"[...] é a doutrina segundo a qual todos os juízos valorativos e, mais especificamente, todos os juízos morais não passam de expressões de preferência, expressões de sentimento ou atitudes, na medida em que são de caráter moral ou valorativo"."12
\end{abstract}

Desse modo, os juízos particulares poderiam reunir elementos morais e factuais. Estes (os elementos fac-

${ }^{12}$ MACINTYRE, Alasdair. Depois da virtude: um estudo em teoria moral. Trad. Jussara Simões. São Paulo: EDUSC, 2001. p. 30. tuais) seriam julgados em termos de "verdadeiro ou falso", existindo critérios racionais a orientar esse julgamento. $\mathrm{E}$ aqueles (os elementos morais), por serem expressões de sentimentos, não seriam nem verdadeiros nem falsos, não sendo possível chegar a um acordo sobre esses elementos por meio de algum método racional, pois tal método simplesmente não existiria. "Chega-se ao acordo, caso se chegue, ao se produzir certos resultados não racionais sobre as emoções ou o comportamento dos que discordam." ${ }^{13}$ Com essas premissas, o emotivismo possui a pretensão de explicar todos os juízos de valor, sejam quais forem. E se isso assim for, diz o pensador comunitarista, "[...] toda discordância moral é racionalmente interminável”.14

Conta-nos, a propósito, MacIntyre: ${ }^{15}$

O emotivismo vem sendo apresentado por seus mais cultos protagonistas, até o momento, como uma teoria acerca do significado dos enunciados utilizados para emitir juízos morais. C. L. Stevenson, o maior expoente da teoria, afirmava que o enunciado "Isto é bom" significa mais ou menos o mesmo que "Aprovo isto; aprove também", tentando captar com essa equivalência tanto a função do juízo moral como expressando as atitudes do falante, quanto à função do juízo moral elaborado para influenciar o comportamento do ouvinte.

Entretanto, na visão do filósofo, a doutrina emotivista fracassa claramente ao pretender explicar o significado dos tipos de enunciados. Ora, se a teoria quer elucidar o significado de determinada classe de enunciados, enfocando a sua função de expressar sentimentos, uma parte essencial dessa teoria deveria consistir na identificação e caracterização dos sentimentos em questão. Porém, enfatiza o comunitarista, os defensores do emotivismo ficam geralmente em silêncio quanto a esse assunto, “[...] pois todas as tentativas, até o momento, de identificar os tipos pertinentes de sentimentos ou atitudes mostraram ser impossível evitar a circularidade vazia": ${ }^{16}$

Os juízos morais expressam “sentimentos ou ati-
tudes" é o que se diz. "Que espécie de sentimen-
tos ou atitudes?", perguntamos. "Sentimentos ou
atitudes de aprovação é a resposta". "Que espécie
de aprovação?", perguntamos, talvez para acres-

${ }^{13}$ MACINTYRE, Alasdair. Depois da virtude: um estudo em teoria moral. Trad. Jussara Simões. São Paulo: EDUSC, 2001. p. 31.

${ }^{14}$ Ibidem.

${ }^{15}$ STEVENSON, 1945 apud MACINTYRE, Alasdair. Depois da virtude: um estudo em teoria moral. Trad. Jussara Simões. São Paulo: EDUSC, 2001. p. 31.

${ }^{16}$ MACINTYRE, op. cit., p. 32. 
centar que existem diversos tipos de aprovação. É na resposta a essa pergunta que todas as versões do emotivismo permanecem em silêncio ou, ao identificar o tipo pertinente de aprovação como aprovação moral - isto é, o tipo de aprovação expressa por um juízo especificamente moral - assume uma circularidade vazia.

Como se vê, há inegavelmente semelhanças entre o que Rawls chama de intuicionismo e o emotivismo segundo a crítica macIntyriana. O próprio MacIntyre é quem o diz. Para ele, "[...] a teoria em questão pegou emprestado do início do século XVIII o nome de 'intuicionismo' e seu progenitor imediato foi G. E. Moore."17 De acordo com o intuicionismo de Moore, definir algo como "bom" seria agregar-lhe uma propriedade não natural, diferente da qualificável como "agradável" ou "propício à sobrevivência evolutiva". As proposições, portanto, que declaram que "isso ou aquilo é bom" são, raciocinando com Moore, verdadeiras intuições; “[...] não são passíveis de prova ou refutação e, de fato, não se pode apresentar nenhuma prova ou raciocínio a favor ou contra essas proposições". ${ }^{18}$ Vale observar aqui a proximidade dessa assertiva, no sentido da impossibilidade de prova ou refutação das intuições, com a crítica rawlsiana à inexistência de uma solução para o problema da definição da prioridade em caso de colisão entre os princípios fundamentais intuicionistas.

Não parece necessário que nos alonguemos com maiores explicações sobre a teoria emotivista na visão de Alasdair MacIntyre. Basta que tenhamos presente sua aposta nas intuições e na inexistência de métodos ou critérios racionais para a explicação dos juízos morais, de maneira que só poderíamos alcançar acordos em tais questões por meio da produção de resultados não racionais sobre as emoções dos que discordam. Isso é suficiente para que direcionemos o presente estudo ao exame - à luz dessas considerações sobre os movimentos do intuicionismo/emotivismo - da técnica decisória da ponderação entre princípios constitucionais, tal como o Supremo Tribunal Federal dela lançou mão no julgamento de um notório "caso difícil" que enfrentou.

\footnotetext{
${ }^{17}$ MACINTYRE, Alasdair. Depois da virtude: um estudo em teoria moral. Trad. Jussara Simões. São Paulo: EDUSC, 2001. p. 35.

${ }^{18}$ Ibidem, p. 36.
}

\section{As críticas ao intuicionismo/emotivismo e a ponderação entre princípios constitucionais: algumas considerações sobre 0 caso Ellwanger}

Apesar dos esforços da doutrina cognominada de "neoconstitucionalista" para dotar a ponderação entre princípios constitucionais de maior racionalidade, parece-nos que, na prática da Suprema Corte brasileira, essa técnica decisória não vem impedindo que julgamentos aconteçam tão-somente por meio de juízos que Rawls e MacIntyre chamariam, respectivamente, de intuicionistas e emotivistas.

Luís Roberto Barroso, um dos conhecidos teóricos do neconstitucionalismo em terrae brasilis, na sua conhecida obra "Interpretação e Aplicação da Constituição", mormente no post scriptum, fez uma descrição muito adotada, na jurisprudência pátria, sobre a técnica da ponderação entre princípios. Dela nos valeremos aqui. ${ }^{19}$

O raciocínio ponderativo teria começado a surgir quando a dogmática jurídica passou a se dar conta dos limites da subsunção - premissa maior (norma) incidindo sobre a premissa menor (fatos) e produzindo a aplicação do direito ao caso concreto -, a qual se teria mostrado incapaz de resolver casos difíceis, que, por sua vez, caracterizar-se-iam fundamentalmente por oferecerem mais de um princípio passível de incidir para a solução da lide. Por exemplo, no confronto entre os direitos à liberdade de imprensa ou de expressão, de um lado, e os direitos à honra, intimidade e vida privada, de outro. Para o equacionamento de situações desse tipo, seria “[...] preciso um raciocínio de estrutura diversa, mais complexa, que seja capaz de trabalhar multidirecionalmente, produzindo a regra concreta que vai reger a hipótese a partir de uma síntese dos distintos elementos normativos incidentes sobre aquele conjunto de fatos."20 Esse raciocínio teria de ser desenvolvido por meio da técnica da ponderação.

${ }^{19}$ É preciso, porém, deixar claro que a descrição do instituto feita por Barroso é uma síntese de um desenvolvimento maior, levado a efeito pelo jurista alemão Robert Alexy vide ALEXY, Robert. Teoria da argumentação jurídica. Trad. Zilda Hutchinson Schild Silva. São Paulo: Landy, 2001; e ALEXY, Robert. Teoria dos direitos fundamentais. Trad. Virgílio Afonso da Silva. São Paulo: Malheiros, 2008.

${ }^{20}$ BARROSO, Luís Roberto. Interpretação e aplicação da Constituição. 6. ed. São Paulo: Saraiva, 2006. p. 357. 
Barroso nos dá uma definição lapidar do fenômeno: ${ }^{21}$

A ponderação consiste, portanto, em uma técnica de decisão jurídica aplicável a casos difíceis, em relação aos quais a subsunção se mostrou insuficiente, especialmente quando uma situação concreta dá ensejo à aplicação de normas de mesma hierarquia que indicam situações diferenciadas.

O jurista decompõe essa técnica decisória em três etapas. Na primeira, cabe ao intérprete detectar as normas relevantes para a solução da lide, identificando eventuais conflitos entre elas. Na segunda etapa, é necessário o exame dos fatos e circunstâncias do caso concreto e sua interação com os elementos normativos, pois "[...] o exame dos fatos e os reflexos sobre eles das normas identificadas na primeira fase poderão apontar com maior clareza o papel de cada uma delas e a extensão de sua influência”. Por fim, no terceiro e último estágio, os diferentes grupos de normas e os fatos, com sua repercussão no caso concreto, devem ser examinados conjuntamente, apurando-se os pesos a serem atribuídos a todos esses elementos, chegando-se, assim, ao grupo de normas que preponderará para a composição do embate. Impõe-se destacar aqui que o intérprete precisará ainda decidir o quão intensamente um grupo de normas preponderará sobre o outro, o que deve ser feito tendo como suporte e balizamento o conhecido "princípio da proporcionalidade", com seus três subprincípios, o da adequação, o da necessidade e o da proporcionalidade em sentido estrito. ${ }^{22}$

Todavia, não obstante todo esse complexo desenvolvimento teórico do raciocínio ponderativo, a sua aplicação prática, ao que nos parece, não vem conseguindo evitar julgamentos proferidos com base apenas em juízos intuicionistas/emotivistas. Para amparar essa assertiva, vejamos o que ocorreu em um dos mais famosos casos da história moderna do Supremo Tribunal Federal, em que houve a aplicação da técnica decisória da ponderação entre princípios constitucionais. É, como adiantado, do Caso Ellwanger que estamos falando (HC 82.424/RS). ${ }^{23}$

Siegfried Ellwanger fora condenado, pelo Tribunal de Justiça do Rio Grande do Sul, por editar e vender livros fa-

\footnotetext{
${ }^{21}$ BARROSO, Luís Roberto. Interpretação e aplicação da Constituição. 6. ed. São Paulo: Saraiva, 2006. p. 358.

${ }^{22}$ Ibidem, p. 358-360.

${ }^{23}$ BRASIL. Supremo Tribunal Federal. Habeas Corpus n. 82.424/ $R S$. Relator original: Min. Moreira Alves. Relator para o acórdão: Min. Maurício Corrêa. Disponível em: <http://www.stj. jus.br>. Acesso em: 18 jul. 2011.
}

zendo apologia de ideias com conteúdo antissemita ou, mais especificamente, de incitamento contra o judaísmo. Mantida sua condenação pelo Superior Tribunal de Justiça, houve a impetração de habeas corpus perante o Supremo Tribunal Federal, no qual a ordem acabou sendo, por maioria de votos, denegada. O inusitado nesse julgamento é que tanto a maioria (representada aqui pelo voto do ministro Gilmar Mendes) como a minoria (representada pelo pronunciamento do ministro Marco Aurélio) valeram-se da técnica da ponderação entre princípios constitucionais. A maioria para negar e a minoria para conceder o habeas. É certo que nem todos os juízes da Corte fizeram essa ponderação de maneira explícita em suas manifestações. Precisamente por isso, é que serão examinados aqui os votos dos ministros Gilmar e Marco Aurélio, nos quais essa técnica decisória foi minudente e expressamente utilizada, chegando-se, no entanto, a resultados diametralmente opostos.

No pronunciamento de Gilmar Mendes, assim foi utilizada a ponderação entre princípios constitucionais: ${ }^{24}$

A par dessa vinculação aos direitos fundamentais, o princípio da proporcionalidade alcança as denominadas colisões de bens, valores ou princípios constitucionais. Nesse contexto, as exigências do princípio da proporcionalidade representam um método geral para a solução do conflito entre princípios, isto é, um conflito entre normas que, ao contrário do conflito entre regras, é resolvido não pela revogação ou redução teleológica de uma das normas conflitantes nem pela explicitação de distinto campo de aplicação entre normas, mas antes e tãosomente pela ponderação do peso relativo de cada uma das normas em tese aplicáveis e aptas a fundamentar decisões em sentidos opostos. Nessa última hipótese, aplica-se o princípio da proporcionalidade para estabelecer ponderações entre distintos bens constitucionais. [...]

Em síntese, a aplicação do princípio da proporcionalidade se dá quando verificada restrição a determinado direito fundamental ou um conflito entre distintos princípios constitucionais de modo a exigir que se estabeleça o peso relativo de cada um dos direitos por meio da aplicação das máximas que integram o mencionado princípio da proporcionalidade: a adequação, a necessidade e a proporcionalidade em sentido estrito. [...] Diante de tais circunstâncias, cumpre indagar se a decisão condenatória atende, no caso, às três máximas parciais da proporcionalidade.

${ }^{24}$ BRASIL. Supremo Tribunal Federal. Habeas Corpus n. 82.424/ RS. Relator original: Min. Moreira Alves. Relator para o acórdão: Min. Maurício Corrêa. Disponível em: <http://www.stj. jus.br>. Acesso em: 18 jul. 2011. 
É evidente a adequação da condenação do paciente para se alcançar o fim almejado, qual seja, a salvaguarda de uma sociedade pluralista, onde reine a tolerância. Assegura-se a posição do Estado, no sentido de defender os fundamentos da dignidade da pessoa humana (art. $1^{\text {a }}$, III, CF), do pluralismo político (art. $\left.1^{\circ}, \mathrm{V}, \mathrm{CF}\right)$, o princípio do repúdio ao terrorismo e ao racismo, que rege o Brasil nas suas relações internacionais (art. $4^{\circ}$, VIII), e a norma constitucional que estabelece ser o racismo um crime imprescritível (art. $5^{\circ}$, XLII).

Também não há dúvida de que a decisão condenatória, tal como proferida, seja necessária, sob o pressuposto de ausência de outro meio menos gravoso e igualmente eficaz. Com efeito, em casos como esse, dificilmente vai se encontrar um meio menos gravoso a partir da própria definição constitucional. Foi o próprio constituinte que determinou a criminalização e a imprescritibilidade da prática do racismo. Não há exorbitância no acórdão.

Tal como anotado nos doutos votos, não se trata aqui sequer de obras revisionistas da história, mas de divulgação de idéias que atentam contra a dignidade dos judeus. Fica evidente, igualmente, que se não cuida, nos escritos em discussão, de simples discriminação, mas de textos que, de maneira reiterada, estimulam o ódio e a violência contra os judeus. Ainda assim, o próprio Tribunal de Justiça do Estado do Rio Grande do Sul agiu com cautela na dosagem da pena, razão pela qual também aqui a decisão atende ao princípio da "proibição de excesso".

A decisão atende, por fim, ao requisito da proporcionalidade em sentido estrito. Nesse plano, é necessário aferir a existência de proporção entre o objetivo perseguido, qual seja a preservação dos valores inerentes a uma sociedade pluralista, da dignidade humana, e o ônus imposto à liberdade de expressão do paciente. Não se contesta, por certo, a proteção conferida pelo constituinte à liberdade de expressão. Não se pode negar, outrossim, o seu significado inexcedível para o sistema democrático. Todavia, é inegável que essa liberdade não alcança a intolerância racial e o estímulo à violência, tal como afirmado no acórdão condenatório. Há inúmeros outros bens jurídicos de base constitucional que estariam sacrificados na hipótese de se dar uma amplitude absoluta, intangível, à liberdade de expressão na espécie. (grifos do autor)

Já Marco Aurélio, após reputar a questão em julgamento como uma das mais importantes - se não a mais importante - por ele apreciadas enquanto juiz da Suprema Corte, lançou mão da ponderação entre princípios constitucionais da seguinte forma: ${ }^{25}$

${ }^{25}$ BRASIL. Supremo Tribunal Federal. Habeas Corpus n. 82.424/ $R S$. Relator original: Min. Moreira Alves. Relator para o acórdão: Min. Maurício Corrêa. Disponível em: <http://www.stj. jus.br>. Acesso em: 18 jul. 2011.
A par de outros enfoques apreciados nos votos dos ministros que me antecederam, o caso denota um profundo, complexo e delicado problema de Direito Constitucional, e daí o tom paradigmático deste julgamento: estamos diante de um problema de eficácia de direitos fundamentais e da melhor prática de ponderação de valores, o que, por óbvio, força este Tribunal, guardião da Constituição, a enfrentar a questão da forma como se espera de uma Suprema Corte. Refiro-me ao intrincado problema da colisão entre os princípios da liberdade de expressão e da proteção à dignidade do povo judeu. Há de definir-se se a melhor ponderação dos valores em jogo conduz à limitação da liberdade de expressão pela alegada prática de um discurso preconceituoso atentatório à dignidade de uma comunidade de pessoas ou se, ao contrário, deve prevalecer tal liberdade. Essa é a verdadeira questão constitucional que o caso revela. [...]

A questão da colisão de direitos fundamentais com outros direitos necessita, assim, de uma atitude de ponderação dos valores em jogo, decidindo-se, com base no caso concreto e nas circunstâncias da hipótese, qual o direito que deverá ter primazia. Trata-se do mecanismo de resolução de conflito de direitos fundamentais, hoje amplamente divulgado no Direito Constitucional Comparado e utilizado pelas Cortes Constitucionais no mundo [...].

Vale ressaltar que essa ponderação de valores ou concordância prática entre os princípios de direitos fundamentais é um exercício que, em nenhum momento, afasta ou ignora os elementos do caso concreto, uma vez que é a hipótese de fato que dá configuração real a tais direitos. [...]

A aplicação do princípio da proporcionalidade surge como o mecanismo eficaz a realizar a ponderação exigida no caso concreto, devido à semelhança de hierarquia dos valores em jogo: de um lado, a alegada proteção à dignidade do povo judeu; de outro, a garantia da manifestação do pensamento. O conteúdo central do princípio da proporcionalidade é formado por subprincípios que abarcam parcialmente certa amplitude semântica da proporcionalidade. São eles a idéia de conformidade ou de adequação dos meios, a exigibilidade ou necessidade desses meios e a proporcionalidade em sentido estrito. Passo, então, à análise do acórdão do Tribunal de Justiça do Rio Grande do Sul - pronunciamento condenatório -, a partir desses subprincípios, sob um ângulo diferente daquele efetuado pelo ilustre ministro Gilmar Mendes.

A. O subprincípio da conformidade ou da adequação dos meios (Geeingnetheit) examina se a medida adotada é apropriada para concretizar o objetivo visado, com vistas ao interesse público. Assim, cabe indagar se condenar o paciente e proibi-lo de publicar os pensamentos, apreender e destruir as obras editadas são os meios adequados para acabar com a discriminação contra o povo judeu ou com o risco de se incitar 
a discriminação. Penso que não, uma vez que o fato de o paciente querer transmitir a terceiros a sua versão da história não significa que os leitores irão concordar, e, ainda que concordem, não significa que vão passar a discriminar os judeus, mesmo porque, ante a passagem inexorável do tempo, hoje os envolvidos são outros. [...].

B. O segundo subprincípio é o da exigibilidade ou da necessidade (Erforderlichkeit), segundo o qual a medida escolhida não deve exceder ou extrapolar os limites indispensáveis à conservação do objetivo que pretende alcançar. Com esse subprincípio, o intérprete reflete, no caso, se não existem outros meios não considerados pelo Tribunal de Justiça que poderiam igualmente atingir o fim almejado, a um custo ou dano menor aos interesses dos cidadãos em geral. [...] Na hipótese, a observância desse subprincípio deixa ao Tribunal apenas uma solução cabível, ante a impossibilidade de aplicar outro meio menos gravoso ao paciente: conceder a ordem, garantindo o direito à liberdade de manifestação do pensamento, preservados os livros, já que a restrição a tal direito não garantirá sequer a conservação da dignidade do povo judeu.

C. Finalmente, o último subprincípio é o da proporcionalidade em sentido estrito (Verhältnismässigkeit), também conhecido como "lei da ponderação". O intérprete deve questionar se o resultado obtido é proporcional ao meio empregado e à carga coativo-interventiva dessa medida. É realizado um juízo de ponderação no qual se engloba a análise de adequação entre meio e fim, levando-se em conta os valores do ordenamento jurídico vigente. [...]. Assim, cumpre perquirir se é razoável, dentro de uma sociedade plural como a brasileira, restringir-se determinada manifestação de opinião por meio de um livro, ainda que preconceituosa e despropositada, sob o argumento de que tal idéia incitará a prática de violência, considerando-se, todavia, o fato de inexistirem mínimos indícios de que o livro causará tal revolução na sociedade brasileira. E mais, se é razoável punir o paciente pela edição de livros alheios, responsabilizá-lo por idéias que nem sequer lhe pertencem, tendo em vista que há outras maneiras mais fáceis, rápidas e econômicas de a população ter acesso a tais pensamentos, como a internet.

Embora tenhamos estendido um pouco com as transcrições acima, isso se fez necessário para retratarmos o conteúdo dos longos votos proferidos pelos juízes (um com aproximadamente 40 e uma confirmação com mais de 20 laudas, e o outro, com quase 70 laudas), bem como para demonstrarmos de uma forma clara que, em ambos os pronunciamentos, a técnica decisória da ponderação entre princípios foi observada na inteireza de seu método. Porém, os resultados, como visto, foram absolutamente diferentes. O ministro Gilmar Mendes entendeu que, depois de ponderados os princípios candidatos a incidir na espécie, o da dignidade do povo judeu seria prevalecente, enquanto o ministro Marco Aurélio concluiu ser o princípio da liberdade de expressão o vencedor na ponderação. Não é difícil constatarmos que a técnica decisória foi utilizada para dar uma roupagem - diga-se assim - de racionalidade às intuições sobre a justiça de cada julgador.

A estrutura dos votos dos ministros foi muito parecida. De início, um relato de alguns aspectos históricos, sociológicos e filosóficos justificadores do valor moral eleito. Depois, uma aproximação desse valor com a situação sub judice. Gilmar Mendes desenvolveu circunstâncias que apontariam ser o ato do paciente, efetivamente, um crime de racismo praticado contra a comunidade dos judeus, seja ela classificada ou não como raça, no sentido estrito da expressão, potencializando o valor dignidade da pessoa humana. Marco Aurélio, por sua vez, traçou uma linha argumentativa valorizadora da liberdade de expressão, concluindo assim pela inexistência de delito penal. Por fim, quando da aproximação de suas convicções sobre tais valores morais ao caso concreto, ambos optaram pelo mesmo caminho para cobrir suas intuições com as vestes de princípios jurídicos: o iter procedimental da ponderação.

A fim de testar a veracidade da nossa afirmação de que os pronunciamentos jurisdicionais foram intuicionistas/emotivistas, é necessário que analisemos a forma como foram justificadas as três máximas do postulado da proporcionalidade como calibrador do raciocínio ponderativo. Para o voto vencedor, a punição do editor dos livros seria um meio adequado para a promoção da dignidade do povo judeu e do pluralismo social, pois, com isso, estar-se-ia assegurando a posição do Estado, no sentido de defender os fundamentos da dignidade da pessoa humana (art. 1a , III, CF), do pluralismo político (art. $\left.1^{\circ}, V, C F\right)$, o princípio do repúdio ao terrorismo e ao racismo, que rege o Brasil nas suas relações internacionais (art. $4^{\circ}$, VIII), e a norma constitucional que estabelece ser o racismo um crime imprescritível (art. $5^{\circ}$, $X L I I)$. Já para o voto vencido, a medida não se revelaria adequada, porque ofato de o paciente querer transmitir a terceiros a sua versão da história não significa que os leitores irão concordar, e, ainda que concordem, não significa que vão passar a discriminar os judeus, mesmo porque, 
ante a passagem inexorável do tempo, hoje os envolvidos são outros. Ora, isso são intuições, apostas baseadas em juízo pessoais de que algo irá ou não ocorrer. Um ministro acredita que, se condenar Ellwanger, alguns fins do Estado serão promovidos. O outro tem a convicção de que, se o condenar, nenhum valor positivo estará promovendo, porquanto acredita que leitor algum passará a discriminar judeus apenas por ler as obras.

Da mesma forma, observemos o que ocorreu com a aplicação da máxima da necessidade. Gilmar Mendes externou o pensamento de que, em casos como esse, dificilmente vai se encontrar um meio menos gravoso [do que a condenação] a partir da própria definição constitucional. Marco Aurélio intuiu que a observância desse subprincípio deixa ao Tribunal apenas uma solução cabível, ante a impossibilidade de aplicar outro meio menos gravoso ao paciente: conceder a ordem, garantindo o direito à liberdade de manifestação do pensamento, preservados os livros, já que a restrição a tal direito não garantirá sequer a conservação da dignidade do povo judeu. Mais uma vez, estamos diante de juízos intuicionistas. Crenças apenas: um juiz acreditando, sem justificar, que dificilmente haverá outra medida menos gravosa para promover o valor dignidade do povo judeu; o outro apostando em que a restrição à liberdade de expressão do editor dos livros não garantirá essa dignidade judaica, sem também explicar o porquê da afirmação.

Quanto à terceira etapa do princípio da proporcionalidade aplicado à ponderação - a proporcionalidade em sentido estrito -, o que se verifica dos votos não é diferente. O primeiro voto transcrito registrou que é inegável que essa liberdade não alcança a intolerância racial e o estímulo à violência, e o segundo, que não é razoável restringir-se determinada manifestação de opinião por meio de um livro, ainda que preconceituosa e despropositada, sob o argumento de que tal ideia incitará a prática de violência, considerando-se, todavia, o fato de inexistirem mínimos indícios de que o livro causará tal revolução na sociedade brasileira. Aqui, ainda que mais bem fundamentados, os pronunciamentos também se limitaram a fazer revelar as intuições dos ministros, uma no sentido de que os livros incitariam a violência e a intolerância racial, de modo que a vedação de sua publicação se imporia; a outra apontando para o fato de que os livros não teriam o condão de provocar essa mesma violência e preconceito, com o que se revelaria desproporcional à medida que tolhesse a sua publicação e, por conseguinte, impusesse a condenação do editor das obras.

Não encontramos em um voto motivos para recusarmos o outro. Eles não dialogam entre si. É claro que ambos podem, em tese, ser considerados constitucionalmente aceitáveis, uma vez que a Constituição, em abstrato, alberga tanto a proteção à dignidade humana quanto a liberdade de expressão, de modo que a decisão pela prevalência de um ou de outro princípio só pode ocorrer em face das circunstâncias do caso concreto. Todavia, essa constatação não pode equivaler a um cheque em branco para o uso livre das intuições, isoladamente consideradas, de cada julgador. É obrigação do magistrado justificar suas escolhas à luz dos fundamentos trazidos pelas partes e dos elementos e contingencialidades da situação posta a julgamento, obrigação essa que é potencializada quando há pronunciamento de membro do órgão colegiado em sentido contrário. Deve haver, portanto, um efetivo debate entre as razões de decidir de cada juiz, um enfrentamento real, na tentativa de que as razões de um não sejam refutadas pelas do outro.

A propósito, não percamos de vista que em nenhum dos dois votos houve contradição interna no uso da ponderação entre princípios. O método foi bem desenvolvido no que concerne à sua coerência lógica. Isso, pois, parece demonstrar que essa técnica decisória, sozinha, não é suficiente para dar respaldo jurídico às intuições pessoais dos juízes. Façamos, no entanto, uma observação aqui: não há nada de errado em lançarmos mão de nossas intuições como ponto de partida de um raciocínio. Elas são próprias do ser humano e talvez seja mesmo inevitável que partamos delas para elaborarmos qualquer juízo moral. O que pode ser colocado em discussão é se elas, por si só, bastam para embasar uma decisão judicial e - mais importante ainda - se a ponderação entre princípios é capaz, na prática, de adequadamente justificá-las, de modo a demonstrar que a intuição de um julgador deva prevalecer sobre a do outro. Lembremo-nos da crítica de John Rawls contra a falta de apresentação, pelo pensamento intuicionista, de critérios que reduzam a discricionariedade na aferição do valor que deve ser priorizado no conflito entre princípios fundamentais. O filósofo não nega a influência das intuições no desenvolvimento dessa tarefa, mas 
acredita que deveríamos reduzir nossa dependência em relação a elas. ${ }^{26}$

É interessante notar ainda que pelo menos o ministro Marco Aurélio já defendeu expressamente que o juiz deve, sim, julgar com base em suas intuições sobre a justiça. Não com essas exatas palavras, mas desta forma: ${ }^{27}$ "Ao examinar a lide, o magistrado deve idealizar a solução mais justa, considerada a respectiva formação humanística. Somente após, cabe recorrer à dogmática para, encontrado o indispensável apoio, formalizá-la”. E talvez o ministro esteja correto nessa assertiva, pelo menos por um ponto de vista. O indispensável é que as intuições sejam testadas e filtradas pela Constituição, com apoio até mesmo em uma teoria sobre a moral ou a justiça, ${ }^{28}$ para que assim se verifique se podem ser justificadas à luz do ordenamento jurídico a que o intérprete está vinculado. Porém, a técnica da ponderação entre princípios isoladamente considerada não parece, a julgar pelo caso Ellwanger, servir para cumprir essa tarefa. Ela, enquanto método que é, pode servir de auxílio ao labor do magistrado, mas, a toda evidência, não poderá sozinha amparar a opção feita pelo decisor por um dos princípios constitucionais colidentes. Caso contrário, corremos o risco

\footnotetext{
${ }^{26}$ No mesmo sentido e porque sobremodo oportuna, vale registrar aqui a visão de outro consagrado filósofo liberal, Ronald Dworkin. DWORKIN, Ronald. Levando os direitos a sério. Trad. Nelson Boeira. São Paulo: M. Fontes, 2010. p. 137, que, ao defender sua teoria da decisão judicial (da única resposta correta), endossa essa preocupação de Rawls: "Os juízes, como qualquer autoridade política, estão sujeitos à doutrina da responsabilidade política. Em sua forma mais geral, essa doutrina afirma que as autoridades políticas devem tomar somente as decisões políticas que possam justificar no âmbito de uma teoria política que também justifique as outras decisões que eles se propõem a tomar. A doutrina parece inócua nessa forma geral, mas ela condena, mesmo em tal forma, um estilo de administração política que poderíamos chamar, com Rawls, de intuicionista. Ela condena a prática de tomar decisões que parecem certas isoladamente, mas que não podem fazer parte de uma teoria abrangente dos princípios e das políticas gerais que seja compatível com outras decisões igualmente consideradas certas". Fugiríamos do objeto deste artigo se fôssemos examinar a viabilidade da teoria de Dworkin para dar coerência argumentativa e justificação consistente às intuições dos juízes. O nosso ponto aqui é apenas reforçar, com a visão de outro liberal, a crítica ao intuicionismo/emotivismo.

${ }^{27}$ BRASIL. Supremo Tribunal Federal. Recurso Extraordinário n. 111.787/GO. Relator original: Min. Aldir Passarinho. Relator para o acórdão: Min. Marco Aurélio. Disponível em: <http://www.stj.jus.br>. Acesso em: 18 jul. 2011.

${ }^{28}$ Adiante voltaremos à indagação sobre a possibilidade de uma decisão judicial amparar-se na ordem jurídica conjugadamente com uma teoria moral ou política.
}

de que o julgamento ocorra apenas com base em juízos - repita-se - intuicionistas/emotivistas, com uma frágil capa de juridicidade. ${ }^{29}$ É de uma atualidade impressionante, a propósito, esta afirmação de MacIntyre ${ }^{30}$ : “[...] o emotivismo não morreu e é importante assinalar com que frequência, em contextos filosóficos modernos bem diferentes, algo bem semelhante à redução que o emotivismo tentou realizar da moralidade à preferência pessoal se repete continuamente nos escritos dos que não se consideram emotivistas".

Aproximando o debate do pensamento de juristas pátrios, encontramos algumas contribuições. Em recente estudo, o ministro aposentado do Supremo Tribunal Federal Eros $\mathrm{Grau}^{31}$ desenvolveu uma contundente crítica à técnica decisória da ponderação, que corrobora a defendida incapacidade dessa técnica de, só por si, dar conformação jurídico-constitucional às intuições pessoais dos juízes. Segundo o ministro, inexiste no sistema jurídico qualquer regra ou princípio a orientar os decisores a propósito de qual dos princípios, no conflito entre eles, deve ser privilegiado, de modo que esse procedimento acaba sendo praticado "[...] à margem do sistema, subjetivamente, de modo discricionário, perigosamente, a partir das pré-compreensões de cada juiz, no quadro de determinadas ideologias". Assim, prossegue Eros, “[...] ou os juízes adotam conscientemente certa posição jurídico-teórica, ou atuam à mercê dos que detém o poder e do espírito do seu tempo, inconscientes dos efeitos de suas decisões, em uma espécie de 'vôo cego', na expressão de Rüthers".

Com o mesmo sentido, temos a investida de outro constitucionalista contemporâneo brasileiro, Lênio Luiz Streck, ${ }^{32}$ que, em texto sugestivamente intitulado "O que é isto - decido conforme minha consciência?", argumenta que a ponderação entre princípios foi sendo transformada, no Brasil, em um enunciado performativo,

\footnotetext{
${ }^{29}$ Juridicidade entendida aqui como parâmetro a ser observado por qualquer ato estatal. Ou seja, a necessidade de que toda emanação do Estado seja respeitante não apenas das leis em sentido estrito, mas do ordenamento jurídico no seu complexo todo de regras e princípios, implícitos e explícitos.

${ }^{30}$ MACINTYRE, Alasdair. Depois da virtude: um estudo em teoria moral. Trad. Jussara Simões. São Paulo: EDUSC, 2001. p. 45.

${ }^{31}$ GRAU, Eros Roberto. Sobre a prestação jurisdicional: direito penal. São Paulo: Malheiros, 2010. p. 40.

32 STRECK, Lenio Luiz. O que é isto: decido conforme minha consciência? Porto Alegre: Livraria do Advogado, 2010. p. 47-48.
} 
não se referindo, portanto, a algo existente nem a uma ideia qualquer. "A sua simples enunciação já faz 'emergir' a sua significação. Portanto, já 'não pode ser contestado'; não pode sofrer críticas; consta como 'algo dado desde sempre". E, dessa forma, "em nome do 'sopesamento entre fins e meios' (a assim denominada 'ponderação'), é possível chegar às mais diversas respostas, ou seja, casos idênticos acabam recebendo decisões diferentes, tudo sob o manto da 'ponderação' e de suas 'decorrências"'.

Ao que parece, as críticas de Rawls e MacIntyre aos movimentos do intuicionismo e do emotivismo nunca estiveram tão atuais, pelo menos se o que estiver em mira for o que Eros Grau chama de o perigoso artifício da ponderação entre princípios ${ }^{33}$ da forma como aplicado pela Suprema Corte no caso aqui investigado. Ora, conquanto o uso como ponto de partida das intuições possa ser considerado inevitável, o intérprete deve ter ciência delas, confessá-las abertamente, e assim desenvolvê-las tendo como balizador o ordenamento jurídico, do qual não poderá, por evidente, desgarrar-se. $\mathrm{O}$ direito posto pelo Estado, aprovado democraticamente pelo Parlamento, tem limites estabelecidos precisamente pelo texto do enunciado normativo, que nunca, por mais complexa que seja a interpretação, pode ser subvertido. Uma vez respeitadas as possibilidades semânticas do texto, a transformação dele em norma, ou seja, do direito em potência no direito em ação, há de ser realizada pelo magistrado "[...] dentro de uma situação histórica determinada, participando da consciência social de seu tempo, considerando o direito todo" ${ }^{\prime 4}$ e levando sempre em conta a realidade subjacente. Nessa tarefa, como adiantado, não parece haver problemas na invocação pelos juízes de sistemas filosóficos ou teorias morais, desde que - nunca é demais reforçar - sejam compatíveis com os princípios e regras constitucionais.

Mais uma vez temos em Eros Grau ${ }^{35}$ - dessa feita quando de seu voto no conhecido processo de extradição do italiano Cesare Battisti - uma boa síntese do que estamos dizendo, mormente quando refere que a receptividade do intérprete à alteridade do texto normativo

\footnotetext{
${ }^{33}$ GRAU, Eros Roberto. Sobre a prestação jurisdicional: direito penal. São Paulo: Malheiros, 2010. p. 37.

${ }^{34}$ Idem. Ensaio e discurso sobre a interpretação/aplicação do direito. São Paulo: Malheiros, 2005. p. 38.

${ }^{35}$ Ibidem, p. 220-221.
}

não pressupõe nem neutralidade diante das coisas nem autocancelação, requerendo, ao contrário, uma matizada incorporação das próprias opiniões prévias e pré-juízos. O que se revela imprescindível, portanto, no processo decisório “[...] é que o intérprete assuma suas próprias antecipações [suas intuições, dizemos nós], com o fim de que o texto mesmo possa se apresentar em sua alteridade e, assim, possa pôr em confronto sua verdade objetiva com as opiniões prévias do intérprete". E isso porque - ainda com Eros, agora também amparado por Nilos Bairros de Brum - o julgador "[...] é condicionado por sua cultura jurídica, suas crenças políticas, filosóficas e religiosas, sua inserção socioeconômica e todos os demais fatores que forjaram e integram sua personalidade". Mas disso não resulta que qualquer texto normativo admita qualquer interpretação. O que, portanto, essas circunstâncias estão a indicar é, fundamentalmente, que o juiz é colocado "[...] em posição preconceituosa (posição de pré-conceito ideológico, seu) perante o texto a interpretar, este também veiculante de mensagem ideológica”.

E se assim o é, o grande debate travado entre liberais e comunitaristas pode fornecer, nesse contexto, um interessantíssimo manancial de argumentos para subsidiar a decisão nos casos difíceis, ${ }^{36} \mathrm{em}$ que há um profundo desacordo moral por trás das teses jurídicas invocadas - não obstante estejam todas amparadas abstratamente pelo sistema constitucional - e, por isso mesmo, em que é impossível se achar uma "solução pronta" no sistema, sendo o raciocínio meramente subsuntivo incapaz de dar conta da composição da lide. Mas alguém poderia objetar que, se os magistrados adotassem essas teorias políticas como contributo à fundamentação de seus votos, estariam atentando contra o princípio majoritário ou contra a segurança jurídica (calculabilidade/previsibilidade do Direito), ambos resultantes da fiel observância das leis positivadas. Essa crítica, a nosso ver, é superficial demais. Peca por não considerar a impossibilidade, já referida, de que encontremos, no ordenamento jurídico, respostas simples para os hard cases. O magistrado, nessas ocasiões, deve optar por algum dos valores conflitantes, todos aceitos, em condições de igual dignidade, pela nossa pluralista Constituição. Fatalmente, pois, será levado a invocar alguma teoria que justifique o valor eleito à luz do caso

\footnotetext{
${ }^{36}$ Dos quais o caso Ellwanger é exemplo típico.
} 
concreto, devendo, à toda evidência, fazê-lo por meio de um ajuste ou uma calibragem entre as circunstâncias fáticas da situação sub judice, a sua intuição, a Constituição interpretada em seu todo e a teoria moral ou política eleita. Cumprirá, assim, o requisito da justificação se a teoria adotada for passível de ser enquadrada na principiologia constitucional, interpretada - repita-se - na sua integridade, sistematicamente.

Poderíamos também enfrentar essa crítica apenas indagando se a técnica da ponderação - sozinha - é capaz de assegurar a observância desses valores democráticos e da segurança jurídica. A resposta nos parece desenganadamente negativa. Basta que atentemos para o habeas corpus, objeto deste estudo. Dois ministros utilizaram o procedimento de modo formalmente impecável, percorrendo todas as suas etapas. Chegaram, todavia, a respostas jurisdicionais opostas. E o que é pior: sem que um voto oferecesse justificativa para que abandonássemos o outro, sem, pois, diálogo ou debate entre si. Os caminhos percorridos só fizeram revelar as intuições de cada juiz. Dessarte, a ponderação entre princípios, tal como realizada, serviu antes para tentar não deixar transparecer a violação aos princípios democráticos e da segurança jurídica, do que para resguardá-los. Aliás, no trabalho referido, Grau também aborda essa questão, concluindo que o mais grave da ponderação entre princípios é, justamente, a incerteza jurídica que pode fazer aportar ao sistema. ${ }^{37}$

Vejamos, agora, o que afirmamos linhas acima: "[...] o debate travado entre liberais e comunitaristas pode fornecer um interessantíssimo manancial de argumentos para subsidiar a decisão nos casos difíceis”. Michael Sandel, outro filósofo comunitarista, na obra "O Liberalismo e os Limites da Justiça", analisa julgamentos que abordaram desacordos morais idênticos ao ocorrido no caso Ellwanger com fundamentos provenientes dessas duas correntes de pensamento. Pergunta Sandel: ${ }^{38}$ "[...] devem os neo-nazis ter o direito de se manifestar em Skokie, Illinois, uma comunidade com um número elevado de sobreviventes do Holocausto? Devem os grupos de suprematistas brancos ser autorizados a publicitar as suas perspectivas racistas?"

${ }^{37}$ GRAU, Eros Roberto. Sobre a prestação jurisdicional: direito penal. São Paulo: Malheiros, 2010. p. 40.

${ }^{38}$ SANDEL, Michael J. O liberalismo e os limites da justiça. Trad. Carlos E. Pacheco do Amaral. 2. ed. Lisboa: Fundação Calouste Gulbenkian, 2005. p. 15.
De acordo com o pensamento do filósofo, ${ }^{39}$ os liberais, em hipóteses como essas, defenderiam que o governo deve assumir uma posição de neutralidade perante as opiniões dos cidadãos. Pode, assim, legislar sobre o momento, o local e o modo de expressão (exemplifica com a proibição de um comício barulhento à noite), mas não tem o direito de impor restrições ao conteúdo do discurso. Isso porque a proibição de expressões ofensivas ou impopulares equivaleria à imposição dos valores de uns sobre os de outros, em desrespeito ao direito de cada indivíduo de escolher e exprimir suas opiniões. Para os liberais, a única possibilidade de imposição de limites à liberdade de expressão é quando dela decorra algum mal importante, como, por exemplo, a violência física. Assim sendo, em conformidade com essa concepção, “[...] a minha dignidade consiste, não em quaisquer papéis sociais que eu possa desempenhar, mas, pelo contrário, na minha capacidade de eleger os meus papéis e a minha identidade para mim mesmo". A concepção liberal, portanto, adota a premissa de que nenhum discurso de ódio pode constituir um mal em si, porquanto o que realmente importa é o respeito do sujeito por si mesmo, independentemente dos seus objetivos ou ligações no seio da sociedade. "Para o sujeito em si, ainda que livre de quaisquer encargos sociais, os fundamentos do auto-respeito antecedem quaisquer ligações ou amarras e, por isso, encontram-se para além do alcance de qualquer insulto 'ao meu povo"'. Precisamente por isso, os liberais não aceitam a imposição de restrições a qualquer discurso, ainda que de ódio, a não ser que, como dito, desse discurso decorra algum dano concreto.

Ainda em consonância com a análise de Sandel, ${ }^{40}$ os comunitaristas poderiam responder a essas objeções argumentando que a concepção liberal de dano é sobremaneira limitada ou restrita. "Para pessoas que se vêem como definidas pelo grupo étnico ou religioso a que pertencem, um insulto ao seu grupo pode causar-lhes um dano tão real e prejudicial como alguns danos físicos". Assim, manifestações com conteúdo nazista ou antissemita deveriam, sim, ser proibidas, em face do potencial

\footnotetext{
${ }^{39}$ SANDEL, Michael J. O liberalismo e os limites da justiça. Trad. Carlos E. Pacheco do Amaral. 2. ed. Lisboa: Fundação Calouste Gulbenkian, 2005. p. 15-16.

${ }^{40}$ Ibidem, p. 16.
} 
que possuem de provocar nos sobreviventes do Holocausto um fundado medo, bem como de evocar-lhes a memória de horrores capazes de atingir o âmago das suas identidades e das suas histórias de vida. Apesar da inexistência de violência física, a identificação do judeu com seu povo, pela força desse elo, deveria ser suficiente para justificar a conjuração ao discurso nazista de ódio.

$\mathrm{O}$ autor comunitarista complexifica ainda mais o debate. ${ }^{41}$ Aduz que o mero reconhecimento do dano causado pelo discurso não é capaz de determinar sua proibição, de modo que o dano deveria ser cotejado com o bem protegido pela liberdade de expressão. “Tal como no caso da religião, também no da liberdade de expressão não basta invocar as exigências de sujeitos densamente constituídos. O que importa é a relevância moral do discurso relativamente ao estatuto moral das identidades enraizadas que esse discurso poderia desfazer ou ofender". E, partindo dessa premissa, apresenta-nos um questionamento: se o discurso nazista deve ser condenado, por que motivo as comunidades segregacionistas do sul dos Estados Unidos não poderiam impedir os manifestantes de direitos civis dos anos 1950 e 1960? "Os segregacionistas do Sul não queriam que Martin Luther King Jr. se manifestasse nas suas comunidades, tal como os residentes de Skokie não queriam ver manifestações neo-nazis nos seus bairros". Desse modo - argumenta Sandel -, assim como os sobreviventes do Holocausto, os segregacionistas poderiam apresentar-se como indivíduos "[...] densamente constituídos em termos sociais, unidos por memórias comuns, que seriam profundamente molestadas pelos manifestantes e pela mensagem por eles apresentada”.

A partir daí, o filósofo critica tanto a solução dada pelo liberalismo como a dada pelo - diga-se assim - comunitarismo clássico. E conclui que a diferença entre ambos os discursos, o nazista e o de Martin Luther, reside no seu conteúdo. Desse modo, seja nos argumentos liberais, que acreditam numa atitude de neutralidade perante o conteúdo do discurso, seja nos argumentos comunitaristas, que definem os direitos como decorrências dos valores dominantes nas comunidades, não se encontraria uma resposta adequada para a necessidade de diferenciarem-se os discursos. "O liberal defenderia

\footnotetext{
${ }^{41}$ SANDEL, Michael J. O liberalismo e os limites da justiça. Trad. Carlos E. Pacheco do Amaral. 2. ed. Lisboa: Fundação Calouste Gulbenkian, 2005.
}

a liberdade de expressão em ambos os casos, passando o comunitarista por cima dela. No entanto, a necessidade de decidir ambos os casos da mesma maneira evidencia a estultice de não se querer emitir juízos de valor, partilhada por liberais e comunitaristas". Assim, o fundamento da distinção entre os discursos prender-se-ia à constatação de que os nazistas promoveram o genocídio e o ódio e Martin Luther King lutou por direitos civis para os negros. Em uma palavra: o conteúdo do discurso seria o seu diferencial. "As memórias partilhadas pelos sobreviventes do Holocausto merecem uma deferência moral, o que não se verifica relativamente à solidariedade entre os segregacionistas".

A análise proposta por Sandel para o desacordo moral sob enfoque é muito rica. Ainda que tenha refutado tanto os argumentos dos liberais como os dos comunitaristas ortodoxos, partiu deles para chegar a uma solução que pode ser tida como uma terceira via ou como um temperamento da visão comunitarista, da qual não se apartou totalmente, dado que admitiu implicitamente a ocorrência de dano à comunidade dos judeus por manifestações de cunho antissemita. Há valores comunitários, portanto, que mereceriam a proteção do Estado contra as manifestações de pensamento, em ordem a restringir a liberdade de expressão, mas não qualquer valor comunitário. O conteúdo do discurso seria a chave para a solução do caso.

Parece-nos que a conclusão de Michael Sandel se coaduna perfeitamente com uma interpretação sistemática da Constituição brasileira, que tipifica como crime manifestações de racismo, afastando-as, de plano, do âmbito de proteção do direito à liberdade de expressão. Porém, não é nossa intenção desenvolver esse ponto. $\mathrm{O}$ que nos interessa aqui é a forma como o problema foi posto por Sandel, valendo-se do debate entre comunitaristas e liberais para enfrentar esse interessante conflito entre princípios. Não teria, portanto, sido melhor se os ministros Gilmar Mendes e Marco Aurélio, em vez de terem lançado mão da técnica da ponderação, houvessem admitido explicitamente suas intuições e as tivessem desenvolvido nos termos propostos pelo filósofo comunitarista cujo pensamento ora examinamos? Acreditamos que sim. Aliás, não é difícil encontrarmos elementos liberais e comunitaristas nos longos votos desses juízes da Suprema Corte. Poderiam, portanto, ter dialogado com essas teorias, em vez de terem optado, ao aproximar suas 
ilações do ordenamento jurídico, por realizar o procedimento do sopesamento entre princípios.

Marco Aurélio ${ }^{42}$ adota, em trechos do seu pronunciamento, posições de caráter nitidamente liberal, dizendo, por exemplo, que há de se proclamar a autonomia do pensamento individual como uma forma de proteção à tirania imposta pela necessidade de adotar-se sempre o pensamento politicamente correto ou ainda que a única restrição possivel à liberdade de expressão do pensamento, de modo justificado, é quanto à forma de expressão, ou seja, à maneira como esse pensamento é difundido. $\mathrm{O}$ ministro argumenta que o tratamento seria diferente se, em vez de ter publicado um livro, Ellwanger estivesse às ruas distribuindo panfletos com dizeres do tipo: "morte aos judeus", "vamos expulsar estes judeus do País", "peguem as armas e vamos exterminá-los" (atos concretos de violência). Mais adiante, retoma a fundamentação no sentido de que apenas atitudes concretamente danosas estariam fora do âmbito de proteção do direito fundamental ao pensamento livre, ou seja, ações exacerbadamente agressivas, fisicamente contundentes ou que exponham pessoas a situações de risco iminente.

Gilmar Mendes, por sua vez, externa posicionamentos que poderiam ser tranquilamente enquadrados no pensamento comunitarista, tal como descrito por Sandel: a discriminação racial levada a efeito pelo exercício da liberdade de expressão compromete um dos pilares do sistema democrático, a própria idéia de igualdade. Posteriormente, no aditamento a seu voto, o juiz é ainda mais claro, afirmando que uma compreensão dos direitos fundamentais que não se assente apenas em uma concepção liberal certamente não pode dar guarida, no âmbito do direito à liberdade de expressão, a manifestações anti-semitas tão intensas com as que ressaem dos autos. Aduz, outrossim, que o exercício dos direitos nas sociedades democráticas não se compatibiliza com a prática de intolerância militante e com ataques à dignidade de grupos ou etnias.

Essas ideias, segundo pensamos, deveriam ter recebido um desenvolvimento maior, confrontando-se-as entre si, com o texto constitucional e com os elementos fáticos do problema jurídico analisado. Desnecessária, portanto, a ponderação entre princípios, que acabou

${ }^{42}$ BRASIL. Supremo Tribunal Federal. Habeas Corpus n. 82.424/ $R S$. Relator original: Min. Moreira Alves. Relator para o acórdão: Min. Maurício Corrêa. Disponível em: <http://www.stj. jus.br>. Acesso em: 18 jul. 2011. servindo apenas como tentativa de ocultar os juízos intuicionistas/emotivistas dos magistrados. Concordamos novamente com Sandel quando refere que " [...] qualquer teoria de direitos exige certas regras e doutrinas gerais [...], no entanto, em certos casos difíceis, o juiz não pode aplicar estas regras gerais, tendo antes que apelar, desde logo, para os objectivos morais que justificam a prática em causa," ${ }^{33}$ devendo desenvolvê-los e complexificá-los à luz do ordenamento jurídico posto e dos elementos do caso concreto, escancarando-os, seja para acatá-los, seja para refutá-los, sempre fundamentadamente.

\section{Observações finais}

As presentes linhas pretenderam tão-somente provocar. Apesar de a ponderação entre princípios constitucionais estar sendo utilizada com cada vez mais frequência nos julgamentos de casos difíceis, é ela, efetivamente, o melhor caminho para a decisão? Qual a intenção do intérprete quando a aciona? Para que fim exatamente vem servindo? Os juízes brasileiros, quando se valem dessa técnica, aperfeiçoam a fundamentação, legitimando democraticamente seus pronunciamentos? Ou dela se utilizam apenas para tentar dar uma roupagem jurídica às suas intuições sobre a justiça? Enfim, esse sopesamento entre princípios constitucionais é uma técnica decisória democrática, capaz de traduzir a consciência social e assegurar a segurança jurídica? Por outro lado, até que ponto é possível aos julgadores empregarem, na fundamentação de suas decisões, as grandes teorias sobre a moral ou sobre a justiça? Qual o melhor meio de fazê-lo?

No desenvolvimento deste estudo, deixamos entremostrar nosso entendimento: a ponderação entre princípios, ao que nos parece, não vem servindo para evitar que as decisões sejam resultado, exclusivamente, de juízos intuicionistas/emotivistas, tampouco para assegurar a certeza do Direito. Amparamos nossa aposta, como visto, na análise de um rumoroso caso (Habeas Corpus 82.424/RS) apreciado pelo Supremo Tribunal Federal, em que o pano de fundo compôs-se de um relevante desacordo moral - dignidade do povo judeu versus liberdade de expressão.

\footnotetext{
${ }^{43}$ SANDEL, Michael J. O liberalismo e os limites da justiça. Trad. Carlos E. Pacheco do Amaral. 2. ed. Lisboa: Fundação Calouste Gulbenkian, 2005. p. 17.
} 
Por outro lado, acreditamos que é possível, sim, que os magistrados se valham, nos hard cases, das teorias morais, desde que, como registrado, aceitas pelo texto constitucional interpretado em seu todo e conjuntamente com a realidade que lhe subjaz. Nesse cenário, o debate entre liberais e comunitaristas, tão pouco explorado pela jurisprudência brasileira, pode ser proveitoso. Em razão desse confronto entre visões de mundo, muito se produziu acerca da justificação dos valores sociais e, para sua utilização no ato de julgar, é necessário, por evidente, que o intérprete efetue a devida filtragem do que pode ou não ser aplicado ao Direito em terrae brasilis. O importante é o esforço hermenêutico a ser feito pelo julgador de modo a evitar uma redução da moral ou mesmo do Direito a um mero exercício de preferências pessoais.

\section{Referências}

ALEXY, Robert. Teoria da argumentação jurídica. Trad. Zilda Hutchinson Schild Silva. São Paulo: Landy, 2001.

ALEXY, Robert. Teoria dos direitos fundamentais. Trad. Virgílio Afonso da Silva. São Paulo: Malheiros, 2008.

BARROSO, Luís Roberto. Interpretação e aplicação da Constituição. 6. ed. São Paulo: Saraiva, 2006.

BRASIL. Supremo Tribunal Federal. Habeas Corpus $n$. 82.424/RS. Relator original: Min. Moreira Alves. Relator para o acórdão: Min. Maurício Corrêa. Disponível em: $<$ http://www.stj.jus.br>. Acesso em: 18 jul. 2011.
BRASIL. Supremo Tribunal Federal. Recurso Extraordinário n. 111.787/GO. Relator original: Min. Aldir Passarinho. Relator para o acórdão: Min. Marco Aurélio. Disponível em: <http://www.stj.jus.br >. Acesso em: 18 jul. 2011.

DWORKIN, Ronald. Levando os direitos a sério. Trad. Nelson Boeira. São Paulo: Martins Fontes, 2010.

GRAU, Eros Roberto. Ensaio e discurso sobre a interpretação: aplicação do direito. São Paulo: Malheiros, 2005.

GRAU, Eros Roberto. Sobre a prestação jurisdicional: direito penal. São Paulo: Malheiros, 2010.

MACINTYRE, Alasdair. Depois da virtude: um estudo em teoria moral. Trad. Jussara Simões. São Paulo: EDUSC, 2001.

RAWLS, John. Uma teoria da justiça. Trad. Jussara Simões. São Paulo: Martins Fontes, 2008.

SANDEL, Michael J. O liberalismo e os limites da justiça. Trad. Carlos E. Pacheco do Amaral. 2. ed. Lisboa: Fundação Calouste Gulbenkian, 2005.

STRECK, Lenio Luiz. O que é isto: decido conforme minha consciência? Porto Alegre: Livraria do Advogado, 2010.

THIGPEN, Robert B.; DOWNING, Lyle A. Liberal and communitarian approaches to justification. The Review of Politics, v. 51, n. 4, p. 533, 1989. 


\section{Para publicar na revista Universitas/JUS, acesse $o$ endereço eletrônico www.publicacoesacademicas.uniceub.br.}

Observe as normas de publicação, para facilitar e agilizar o trabalho de edição. 